\title{
An open trial of vacuum penile tumescence: constriction therapy for neurological impotence
}

\author{
L Heller MD, ${ }^{1,2} \mathrm{O}$ Keren MD, ${ }^{1,2} \mathrm{R}$ Aloni MA, ${ }^{1 *} \mathrm{G}$ Davidoff $\mathrm{MD}^{1-4 * *}$
}

${ }^{1}$ Loewenstein Hospital, Rehabilitation Center, 278 Ahuza, PO Box 3, Ra'anana, Israel;

${ }^{2}$ Department of Rehabilitation Medicine, Sackler School of Medicine, Tel Aviv University, Ramat Aviv, Israel; ${ }^{3}$ Rehabilitation Medicine Service, Veterans Affairs Medical Center, Ann Arbor, Michigan, USA; ${ }^{4}$ Department of Physical medicine and Rehabilitation, University of Michigan, Ann Arbor, Michigan, USA.

\begin{abstract}
Sexual dysfunction is a frequent result of traumatic and non traumatic neurological disorders, including spinal cord injury, stroke, traumatic brain injury and autonomic neuropathy (for example, as may be seen in patients with diabetes mellitus). Although many methods have been suggested for the treatment of some of these problems in male patients, most are invasive and have a substantial morbidity. This is the report of a pilot trial of vacuum tumescence constriction therapy for 30 patients with chronic neurological impotence. Seventeen of these patients, following sexual counselling and training, decided to purchase such a device. At follow up, a mean of 21 months, over $50 \%$ of those who had purchased the device were still actively using it. The frequency of coitus increased from $0.3 / \mathrm{wk}$ to $1.5 / \mathrm{wk}(\mathrm{t}=-5.7 ; p<0.0001)$. No significant morbidity was reported by patients. Vacuum tumescence constriction therapy shows promise as a noninvasive method for the treatment of neurological impotence.
\end{abstract}

Key words: male neurological impotence; vacuum penile constriction tumescence.

\section{Introduction}

Sexual dysfunction frequently results from traumatic and non traumatic neurological disorders, including spinal cord injury, stroke, traumatic brain injury and autonomic neuropathy. Rehabilitation studies indicate that the restoration of sexual functioning, particularly the ability for men to be able to achieve penetration and sustain an erection, is considered to be very important. ${ }^{1,2}$

Methods commonly reported for the treatment of neurological impotence include either a rigid or an inflatable surgically implanted penile prosthesis; ${ }^{3-6}$ and intracavernous injection of vasoactive substances, such as papaverine, either alone or in conjunction with alpha adrenergic blockage..$^{7-9}$ These methods have a significant morbidity, including infection, dislocation of the prosthesis, priapism and hypoten-

\footnotetext{
${ }^{*}$ Correspondence. ${ }^{* *}$ Died 1991.
}

sion. ${ }^{10,6}$ There is also a very limited treatment experience with the use of vacuum tumescence constriction therapy (VTCT) for the treatment of neurological impotence. Initial reports of the use of VTCT appear to show promise. ${ }^{11-14}$ If VTCT could be shown to have a lower morbidity than either injections or surgical implants, it could be preferred as the first method for the management of neurological impotence. We describe a pilot study of 30 patients who were evaluated for the use of this device in conjunction with sexual counselling at the Loewenstein Hospital Rehabilitation Center in Ra'anana, Israel.

\section{Methods}

All patients were referred for an initial evaluation by the Sexual Disability Clinic at the Loewenstein Hospital Rehabilitation Center, Ra'anana, Israel. They had up to 3 interviews in open question format, both 
individually and with their sexual partner. Questions surveyed both the patient's and the partner's previous sexual histories prior to and following the onset of the neurological disability. Sexual histories were obtained with regards to libido, quality of the patient's erection, ability to achieve orgasm, ability to achieve penetration for substantial length of time, and ability to achieve ejaculation, both prior to and following the onset of the disability.

Options for the management of impotence included pharmacologic, VTCT and surgical implantation of a prosthesis. In cases where couples chose VTCT as the first treatment for neurological impotence, a sexuality counselor presented the VTCT to both partners and explained the technique and the utilization of the VTCT in their sex life. Then they were referred to a physician for at least 3 visits. During these visits the patients were accompanied by their sexual partner. The patient and partner were then trained in the use of the device. The goal was for the patient and partner to be independent in donning and doffing the device without any medical assistance. This training was also accompanied by intensive individual and partner therapy with a sexuality counselor. Two different VTCT devices were used, based on patient/couple preference (Erecaid system, Osborn Medical Systems, Augusta, Georgia, USA; Ved brand vacuum system, Mission Pharmaceuticals, San Antonio, Texas, USA). Both systems operate in a similar fashion: an acrylic cylinder is placed around the penile shaft, and a set of rubber bands or rings are applied to the penile shaft at the lip of the device. The cylinder is then removed for coitus.

Following this training period, patients were offered the opportunity to purchase the device for regular use at home, and they were followed at 6-month intervals by the physician and the sexuality counselor, who completed a follow up questionnaire concerning the effect of the VTCT on the couple's sexual relationship.

All means are given $(-+) 1$ standard deviation. Comparisons in the frequency of coitus both before and after the VTCT program were made, using paired t-tests.

\section{Results}

Thirty patient couples chose VTCT for the initial treatment modality for neurological impotence. The diagnosis of the patients included paraplegia (10), paraparesis (7), hemiplegia (7), quadriplegia (2), multiple sclerosis (2) and autonomic neuropathy (2). Twenty-one patients were married; all patients were sexually active. Seventy-four percent (17/23) of all patients who were sexually active had been engaged in monogamous relationships for the previous year prior to evaluation for VTCT.

Following clinical training, $17(57 \%)$ of the original 30 patients purchased the VTCT device. The only patient group that refused outright to purchase the device were patients who had complete quadriplegia $(n=2)$. The mean time from purchase to the most recent clinical follow up was 21 $(-+) 11.7$ months (range 3 to 36 months). At the last clinic follow up, 9 patients continued to use the device on a regular basis, of the original 17 who had purchased the device $(53 \%)$. The recorded frequency of coitus among those patients who purchased the device was 0.3 per week prior to VTCT training, and 1.5 per week at follow up $(\mathrm{t}=-5.7 ; \quad p<0.0001)$. Following VTCT training all patients were independent in the use of the device with the assistance of their partner, and 90\% (27/30) of the patients were totally independent in donning and doffing the device.

At follow up each of the 17 couples were interviewed regarding their satisfaction with their sexual relationship, as well as relating any problems that they were having using the VTCT. Eighty-three percent of patients reported that they were very satisfied, and $100 \%$ of sexual partners indicated they were very satisfied with their present sexual relationship. This enhancement in satisfaction was attributed to the following: patients felt that they had a greater ability to give pleasure to their sexual partner, and as a result had an increased desire to engage in sexual activity; whereas partners felt this enhancement was secondary to engaging in a more 'natural' sexual relationship. There was no change in the prevalence of ejaculation before or after VTCT training. Regard- 
ing ejaculation, one third of the patients were never able to achieve ejaculation post onset, half reported ejaculation occasionally and $16 \%$ reported having ejaculation always associated with orgasm. (It should be stated that no change in ejaculation was observed after using VTCT. Patients not ejaculating or having partial ejaculation was due to their spinal cord injury, and had nothing to do with VTCT).

Morbidities associated with the use of VTCT were very low. There were no reports of any associated upper or lower urinary tract infection with the use of the device. Seventeen percent (3/17) of the patients complained of suction around the testicles with VTCT use, and another third complained that this sometimes occurred. Seventeen percent (3/17) reported occasional swelling of the testicles, and one third reported petechial hemorrhages. There were no technical problems reported with the device. All of the above problems were of a temporary nature and resolved within a few hours after the use of the VTCT device.

\section{Discussion}

Neurological impotence is a very difficult problem to treat both physically and psychologically for those involved with the rehabilitation of patients. Intracavernous injections of vasoactive substances are popular with some patients because they can be performed by the patient himself or by his sexual partner. ${ }^{7-9}$ However, side effects include pain and paraesthesia, bruising and fibrotic changes at the injection site. ${ }^{7-9}$ Priapism is a rare but serious side effect. ${ }^{8}$ Intracaverous injection therapy appears to be less effective for patients with vascular causes of impotence (eg autonomic neuropathy). ${ }^{8}$

In many studies there are reports of the use of a semirigid or inflatable penile prosthesis for the treatment of neurological impotence. ${ }^{3-6}$ The problems with such devices include the cost; difficulties with payment by some third-party payers; and certain side effects which may include infection with the subsequent necessity for the removal of the prosthetic implant; also erosion and extrusion of the prosthesis. ${ }^{3-6,10}$

In this study, 30 patients underwent a trial with VTCT therapy for neurological impotence. Following the counseling and training program, 17 of the 30 elected to purchase the VTCT unit for use with their sexual partner. At follow up, 53\% of the patients were still sexually active using the VTCT device with no complications such as urinary infection, swollen testicles, or petechial bleedings (these settled after a few days). Patients could use the VTCT within a week of tuition. We suggest that VTCT should be used as the first step in the management of patients with chronic neurological impotence, in association with an intensive sexual counseling program for both the patient and his partner. Although some patients may prefer and benefit from a more invasive method for the treatment of neurological impotence, VTCT is to be preferred as the first treatment of choice because it is noninvasive and is totally reversible.

\section{Acknowledgements}

This study was supported by a research training grant by the National Institute on Disability and Rehabilitation Research, US Department of Education, Washington, DC (H133-P80037), and the US-Israel Educational Foundation, Tel Aviv, Israel.

\section{References}

1 Cole TM (1975) Sexuality and physical disabilities. Arch Sex Behav: 4: 389-403.

2 Hanson RW, Franklin MR (1976) Sexual loss in relation to other functional losses for spinal cord injured males. Arch Phys Med Rehabil 57: 291-293.

3 Van Arsdalen KN, Klein FA, Hackler RH, Brady SM (1981) Penile implants in spinal cord injury patients for maintaining external appliances. J Urol 126: 331-332.

4 Iwatsubo E, Tanaka M, Takahashi K, Akatsu T (1986) Non-inflatable penile prosthesis for the management of urinary incontinence and sexual disability of patients with spinal cord injury. Paraplegia 24: 307-310.

5 Scott FB, Bradley WE, Timm GW (1973) Management of erectile impotence: use of implantable inflatable prosthesis. Urology 2: 80-82. 
6 Small MP (1978) Small-Carrion penile prostheses: a report on 160 cases and review of the literature. J Urol 119: 365-368.

7 Sidi AA, Cameron JS, Dykstra DD, Reinberg Y, Lange PH (1987) Vasoactive intracavernous pharmacotherapy for the treatment of erectile impotence in men with spinal cord injury. J Urol 138: 539-542.

8 Lloyd LK, Richards JS (1989) Intracavernous pharmacotherapy for management of erectile dysfunction in spinal cord injury. Pareplegia 27: 457-464.

9 Wyndaele JJ, de Meyer JM, de Sy WA, Claessens H (1986) Intracavernous injection of vasoactive drugs, an alternative for treating impotence in spinal cord injury patients. Pareplegia 24: 271-275.

10 Kabalin JN, Kessler R (1988) Infectious complications of penile prosthesis surgery. J Urol 139: 953-955.

11 Zasler ND, Katz PG (1989) Synergist erection system in the management of impotence secondary to spinal cord injury. Arch Phys Med Rehabil 70: 712-716.

12 Lloyd EE, Toth LL, Perkash I (1989) Vacuum tumescence: an option for spinal cord injured males with erectile dysfunction. SCI Nursing 7: 25-28.

13 Chancellor MB, Hills E, Schwarts M, Hirsch IH (1991) Treatment of erectile dysfunction in males with spinal cord injury using the vacuum constriction devide (VCD). J Am Paraplegia Soc 14: 73.

14 Nadig PW, Ware JC, Blumoff R (1986) Noninvasive device to produce and maintain an erection-like state. Urology 27: $126-131$. 